\title{
Time-Varying Exchange Rate Exposure: Evidence From Emerging Markets
}

\author{
Prabhath Jayasinghe
}

\begin{abstract}
Using weekly data obtained from three emerging market economies, this study looks into the time-varying characteristic of exchange rate exposure coefficients. In doing so, unlike in some previous studies, exchange rate exposure is viewed through the eyes of an investor in the relevant country. The analysis is carried out using country-level stock indexes and trade-weighted exchange rates. Time-varying exchange rate exposure coefficients are obtained by estimating a multivariate BEKK-GARCH-M model with explicit focus on the non-orthogonality between exchange rate changes and market returns. The findings of the study indicate that, although they are likely to vary over time, exchange rate exposure coefficients of two out of the three cases follow mean-reverting long-memory processes. The presence of mean-reverting exchange rate exposure coefficients has important implications for investment and hedging strategies. In addition, time-varying exchange rate exposure coefficients turn out to be more volatile than respective market betas.
\end{abstract}

Keywords: fractionally integrated processes; International Capital Asset Pricing Model; multivariate GARCH-M models; time-varying exchange rate exposure

JEL Classification: C22; F31; F37; G12; G15

\section{Introduction}

The exposure of firms' profits to exchange rate changes, commonly known as exchange rate exposure, is three- fold: accounting, transactions and operating exposure. Accounting exposure refers to the change in value of a firm's foreign currency denominated accounts in response to a change in the exchange rate that occurred after the transaction had taken place. Transaction exposure refers to the changes in the value of the cash flows that stem from

Prabhath Jayasinghe, $\boldsymbol{P h D}$ is a Professor in the Department of Business Economics, Faculty of Management \& Finance, University of Colombo. E-mail: prabhath@dbe.cmb.ac.lk 


\section{NSBM Journal of Management}

Vol. 1, No. 2, July-December, 2015

contracts entered into prior to a change in exchange rates and to be received/paid after the change in exchange rates. Finally, operating exposure refers to the change in a firm's future operating cash-flows caused by unexpected changes in exchange rates. The second and third elements of exposure are mostly considered together in the literature and are jointly called economic exposure. Following this common practice, the term 'exchange rate exposure' in this study refers to the two components known as 'economic exposure.'

Taking the firm value as a sufficient proxy for firms' expected cash flows, exchange rate exposure is commonly measured as the impact of exchange rate changes on stock returns. As such, exchange rate exposure is estimated using the equation suggested for capital asset pricing model (CAPM) augmented by another independent variable that represents exchange rate changes. The coefficient associated with the exchange rate changes is expected to indicate the firms' exchange rate exposure and is usually known as the exchange rate exposure coefficient. Following the tradition that the coefficient of the market returns is known as market beta, sometimes the coefficient of the exchange rate changes in such a specification is also known as exposure beta (Bodnar \& Wong 2003; Dominguez \& Tesar 2000, 2006).

This approach which does not allow for the time-varying nature of exchange rate exposure to be reflected in exposure coefficients implicitly assumes that exchange exposure remains unchanged over time. Nevertheless, there are several reasons for assuming that exchange rate exposure is time-varying. First, the share of exports and imports in industries may change drastically over time due to both external and internal factors ${ }^{1}$. Changes in demand due to the rise of new competitors in the international arena are an example of the former while the introduction of trade liberalization policies is an example of the latter. Second, as substitutes are being introduced, elasticity of demand for a country's exports and the competitive structure of industries are likely to change over time. Allayannis and Ihrig (2001) argue that the changes in competitive structure affect the exchange rate exposure of industries. Third, financial market deregulations and liberalization attempts may lead to changes in foreign investments in local financial assets which, in turn, affect the exchange rate exposure of a country's stock index. Fourth, the change in location of production of MNCs in response to persistent strong currency positions may lead to changes in the sensitivity of sectoral returns to exchange rate changes. Fifth, incidents like the 1997 and 2008 financial crises may lead to remarkable volatility changes in exchange rate markets.

$\overline{1}$ Allayanis (1997) observes that the status of some US industries change from net exporters to net importers within the same sample period. 
This study examines the time varying nature of the exchange rate exposure of country level stock returns in three emerging market economies: Korea, Taiwan and Thailand. It also looks into certain aspects of the underlying the stochastic structure of exposure betas. While using the methodology adopted in Jayasinghe, Tsui and Zhang (2014), it goes a step further by incorporating two important features. First, this study uses weekly data to check the robustness of their findings which are based on daily data. One can argue that the evidence for time-varying exchange rate exposure associated with daily returns may not be a surprising finding because a day is a very short return horizon. Second, based on tradeweighted exchange rates of the relevant currency, the present study views exchange rate exposure through an investor in the relevant country whereas Jayasinghe et al. (2014) views exchange rate exposure through a US investor in terms of bilateral exchange rates between the US dollar and the relevant currency. As discussed in Section 3, the use of trade-weighted exchange rates is more appropriate within the Adler and Duma's (1983) ICAPM framework than the use of bilateral exchange rates.

An important empirical finding of the paper is that, although exchange rate exposure betas are likely to vary over time, in at least some cases, they follow mean-reverting long-memory processes. The presence of mean-reverting exchange rate exposure coefficients has important implications for investment and hedging strategies. However, in some emerging markets, the time-varying exposure coefficient is not mean-reverting and hence non-stationary.

The rest of this paper is organized as follows. The next section provides a brief literature review. This is followed by the conceptual framework of the study. Econometric methodology is elaborated thereafter. The next section presents the information related to the data and a preliminary analysis of the returns and exchange rate series. The main empirical findings are reported in thereafter followed by concluding remarks.

\section{A Brief Literature Survey}

In the exchange rate exposure literature, there are three groups of studies that capture the time-varying nature of exchange rate exposure in their analyses. The first group uses some simple statistical analyses for this purpose. For instance, Dominguez and Tesar (2006) divide the sample period into a few sub-periods and estimate an exposure coefficient for each sub-period. Williamson (2001) uses dummy variables to distinguish between sub-periods to observe that the exposure is time-variant. Alternatively, Entoff and Jamin (2003) use overlapping moving window regressions to show the time-varying behaviour of the exchange 


\section{NSBM Journal of Management}

Vol. 1, No. 2, July-December, 2015

rate exposure of a bunch of German firms. Bodner and Wong (2003) also use moving window regressions with various return horizons $(1,3,6 \text { and } 12 \text { months })^{2}$.

The second group of studies uses pre-specified determinants of exposure to analyze the timevariation of exposure. Allayannis (1997) finds evidence that exchange rate exposure of US manufacturing industries varies systematically over time with the monthly share of imports and exports in the industry. Using an appropriate model to accommodate this relationship, the study cites evidence for time-variation of exposure in some 4 digit level SIC industries. He reports that the same data set at industry level show significant exchange rate exposure only when the exposure is assumed to be time-varying. Allayannis and Ihrig (2001) inquire into the same phenomenon in terms of three determinants of exposure: (a) an industry's competitive structure where it sells its products; (b) the interaction of the competitive structure of the export market and the export share; (c) the interaction of the competitive structure of the imported input market and its imported input share. Markups are used as a measure of the competitive structure. Bodner et al. (2002) suggest a somewhat similar model in terms of time-varying exchange rate pass-through, though they are not able to show any significant evidence for time-varying exposure. Chiao and Hung (2000) use the same determinants appearing in Allayannis (1997) to examine the time variation in the exchange rate exposure of Taiwanese exporting firms. In addition, they employ dummy variables to check whether exchange rate exposure is affected by the timing of three liberalization effects introduced within the economy. Bodnar and Gentry (1993) add a few more variables to the list of pre-specified determinants of exposure, namely, whether the relevant industry produces traded or non-traded products, the amount of internationally-priced inputs used and the industry's foreign direct investment. In attempting to find the determinants of the exchange rate exposure of Japanese firms, Chow and Chen (1998) use three proxies for the hedging incentives which, in turn, depend on firm size. In addition to aggregate export and import shares to GDP, Entorf and Jamin (2003) use the absolute distance between exchange rates and their long-run mean as a determinant of exposure.

The findings of the second group of studies are more appealing than those of the first group as they show the determinants of the time-variation in exposure as well. These include factors like time-varying export and import shares, markups and pass-through. Nevertheless, those studies are not without limitations. First, the studies that analyze the time-variation in exchange rate exposure in terms of a set of pre-specified variables implicitly rely on a somewhat questionable assumption that there are no other (left out) determinants of time-

$\overline{2}$ Dominguez and Tesar (2006) and Williamson (2001) employ Seemingly Unrelated Regressions (SUR). Bodnar and Wong (2003) rely on Generalized Method of Moments (GMM). 
variation. However, mainly due to the absence of theoretical explanations of such relationships, there may be unidentified factors which are yet important in explaining the time-variation in exposure. Second, the unavailability of data for much shorter return horizons may force the researchers to ignore some determinants or use unsuitable proxies ${ }^{3}$. Moreover, if the return horizon in question is a day, the data for some variables may not be available with daily frequency. Third, the above studies seem to have neglected the impact of the timevarying volatilities which is one of the major and crucial determinants of model parameters and their time-varying element. Fourth, the underlying stochastic structure of the exchange rate exposure betas is largely left unexamined. For instance, such studies do not answer the question whether the time-varying exposure betas are mean-reverting.

The third group of studies, which include Hunter (2005), Lim (2005), Jayasinghe et al. (2014) and Long, Tsui and Zhang (2014) use time-varying second moments to derive time-varying exchange rate exposure coefficients. While Hunter (2005) analyzes the timevarying exchange rate exposure of small and large firms using Fama-French-type size-based portfolios, Lim (2005) derives the time series of both market and exposure betas at country level. More importantly, Lim allows for non-orthogonality between the factors, a feature that Hunter fails to accommodate. Unlike Hunter (2005) or Lim (2005), Jayasinghe et al. (2014) and Long et al. (2014) directly use the mean structure of conditional ICAPM theorized by Adler and Dumas (1983) and made econometrically feasible by De Santis and Gerard (1998) to derive time-varying exposure betas. They also look into certain aspects of the stochastic structure of exposure betas and report that time-varying exposure betas are likely to be mean reverting and follow long-memory processes.

\section{Conceptual Framework}

In a hypothetical world in which purchasing power parity (PPP) holds, exchange rate risk emanates solely from unexpected inflation. The asset holding of a representative investor in such a context is characterized by two types of portfolios: (a) a world market portfolio of risky assets; and (b) 'a personalized hedge portfolio which constitutes the best protection against inflation as [the investor] perceives it'. As such, the expected return on an asset may consist of two parts: the market premium which depends on the asset's world market risk and an additional premium which depends on its usefulness in hedging purchasing power risk. Assuming a world with $L+1$ number of countries (and currencies), the expected excess return on equity $\mathrm{i}$ is formally expressed as:

3 For instance, Allayannins and Ihrig (2001) make an assumption that markups vary on an annual basis, though they work with monthly data, due to the unavailability of markups on a monthly basis. 


$$
E_{t-1}\left(r_{i, t}\right)=\lambda_{m, t-1} \operatorname{Cov}_{t-1}\left(r_{i, t}, r_{m, t}\right)+\sum_{l=1}^{L} \lambda_{\pi, l, t-1} \operatorname{Cov}_{t-1}\left(r_{i, t}, \pi_{l, t}\right)
$$

In Equation 1, $E_{\mathrm{t}-1}($.$) and \operatorname{Cov}_{\mathrm{t}-1}($.$) are expectations and covariances conditional on the current$ information set $I_{t-1} ; \mathrm{r}_{i, t}$ is excess return on a certain asset $i ; \mathrm{r}_{m, t}$ is excess return on world market portfolio; $\pi_{I, t}$ is the inflation rate in country $l$. The conditional covariance between $r_{i, t}$ and $r_{m, t}$ represents the world market risk and, as in the case of standard CAPM, $\lambda_{m, t-1}$ is known as the market price of risk. The conditional covariances between $r_{i, t}$ and $\pi_{I, t}$ represent both inflation and currency risk that stem from PPP violations. Specifically, $\lambda_{\pi, \mathrm{I}, \mathrm{t}} \operatorname{Cov}_{\mathrm{t}-1}(.) \mathrm{r}_{\mathrm{i}, \mathrm{t}} \pi_{\mathrm{I}, \mathrm{t}}$ is the inflation premium that the investor demands for the co-movement between the asset's nominal return and the inflation in the $l^{\text {th }}$ country.

A more parsimonious version of the above model can be obtained by adopting a tradeweighted exchange rate, which may represent the relationship between the currency of the country, to which the asset in question belongs, and L number of other currencies (Giurda and Tsavalis, 2004). Then L number of currency premiums can be replaced by a single currency premium as follows:

$$
E_{t-1}\left(r_{i, t}\right)=\lambda_{m, t-1} \operatorname{Cov}_{t-1}\left(r_{i, t}, r_{m, t}\right)+\lambda_{x, t-1} \operatorname{Cov}_{t-1}\left(r_{i, t}, r_{x, t}\right)
$$

where $r_{x, t}$ is the change in the relevant trade-weighted exchange rate in time $t$. The ICAPM relationship represented by Equation 2 can also be expressed as follows:

$$
E_{t-1}\left(r_{i, t}\right)=\beta_{m, t-1} E_{t-1}\left(r_{m, t}\right)+\beta_{x, t-1} E_{t-1}\left(r_{x, t}\right)
$$

Where $\beta_{m, t-1}$ and $\beta_{x, t-1}$ are market beta and the exchange rate exposure coefficient (beta), respectively. $\beta_{m, t-1}$ measures the asset's exposure to market risk while $\beta_{x, t-1}$ measures its exposure to currency risk. Viewed from this perspective, the time-varying nature of the second moments makes both betas time-varying. The intuition is that, while the expected returns on an asset is proportional to market returns and exchange rate changes, depending on the conditioning information that is publicly available at time $t-1$, the proportionality factors (market and exchange rate exposure betas) themselves are also time-varying. In other words, the investors are sensitive to 'the new information that periodically becomes available to [them], who then use it to adjust their investment strategies' (Harvey, 1991).

Within the above framework, the focus is on the return on financial assets in a few emerging markets. The return on the relevant country stock index is assumed to be a reasonable proxy 
for the return on an asset in that country. The ICAPM relationship represented by Equation 2 is applied to each country. Viewed from this perspective, the return on a certain country stock index can be explained in terms of the covariance between the returns and the return on the world market portfolio and the covariance between the returns and the changes in the selected trade-weighted exchange rate. Obviously, this is a too simplified specification of the original Adler and Dumas (1983) model. However, the information loss that may stem from making the model simple has been neglected as the main objective of the study is to derive exchange rate exposure betas, but not to test the validity of the Adler and Dumas (1983) version of ICAPM ${ }^{4}$.

Contrary to the common practice, returns are not converted into a common/reference currency. Returns on each country index are measured in the relevant local currency. A valueweighted world market index which is not converted into a common/reference currency has also been selected. The purpose of selecting indexes that are not converted into a common/ reference currency is to obtain country level portfolios and a world market portfolio which are free from exchange rate fluctuations (MSCI, 1998). The author's reluctance to convert returns on country indexes and the world market index into a common currency is due to a few theoretical and empirical reasons. First, it helps to separate market risk from currency risk. As Giannopoulos (1995) argues, these two risks are not additive and conversion of various country stock index returns into a common currency will have an adverse impact on their volatility. Second, conversion of country index returns (the dependent variable) into US dollars using the exchange rate chosen would lead to inaccurate exposure coefficients because the changes in the same exchange rate is an independent variable in the regression ${ }^{5}$. Third, conversion of the returns on a world market index denominated in a common currency (mostly in US dollars) into local currency might have resulted in an unaffordable degree of multicolinearity between the two regressors. In addition to the resultant inefficient parameter estimates, it would also lead to unrealistic estimates of exchange rate exposure beta.

\footnotetext{
4 See De Santis and Gerard (1998) and Cappiello et al (2003), for attempts to test the validity of ICAPM using a set of countries and a number of relevant exchange rates.

5 Strictly speaking, this exercise is done using the exchange rates moderated by the base year rate. However, there exists a strong correlation between a series converted using the moderated exchange rates and a series converted using the current rates.
} 


\section{NSBM Journal of Management}

Vol. 1, No. 2, July-December, 2015

\section{Econometric Method}

Assuming constant prices for market risk and currency risk ${ }^{6}$ and that the market returns and exchange rate changes are not necessarily orthogonal, a trivariate BEKK-GARCH ( $p, q$, $\mathrm{K})-\mathrm{M}$ model is employed to estimate time-varying exchange rate exposure coefficients.

$$
\begin{aligned}
& r_{j, t}=\lambda_{0, j}+\lambda_{X} h_{X, t}+\lambda_{M} h_{M, t}+\theta_{j} \varepsilon_{j, t-1}+\varepsilon_{j, t} \\
& j=i, m, x \\
& z_{t}=\varepsilon_{t} H_{t}^{-1 / 2} \\
& \varepsilon_{t}\left|I_{t-1}=\left(\varepsilon_{i, t} \varepsilon_{m, t} \varepsilon_{x, t}\right)^{\prime}\right| I_{t-1} \sim N\left(0, H_{t}\right) \\
& H_{t}=C^{\prime} C+A^{\prime} \varepsilon_{t-1} \varepsilon_{t-1}^{\prime} A+B^{\prime} H_{t-1} B \\
& H_{t}=\left[\begin{array}{ll}
H_{t}^{u u} & H_{t}^{u v} \\
H_{t}^{v u} & H_{t}^{v v}
\end{array}\right] \\
& \mathrm{B}=\left[\begin{array}{ll}
H_{t}^{v v} & ]^{-1} H^{v u}
\end{array}\right.
\end{aligned}
$$

where $r_{j, t}$ is $3 \mathrm{x} 1$ vector that consists of three elements: return on country index at time $t\left(r_{i, t}\right)$, return on world market portfolio at time $t\left(r_{m, t}\right)$ and changes in trade-weighted nominal exchange rate between the currency of country $i$ and other currencies at time $t\left(r_{x, t}\right)^{7}$. An intercept and a MA (1) term is included in each of the three mean equations in order to capture any remaining risk or market inefficiencies. $\varepsilon_{t}$ is a $3 \times 1$ vector of residuals from mean equations in (4), which are assumed to be normally distributed with mean 0 and variance $H_{t}$, which is a $3 \times 3$ variance-covariance matrix. And, $\varepsilon_{t} \mid I_{t-1}$ denotes the vector of random shocks at time $t$ given all available information at time ( $t-1)$. In addition, $h_{X, t}$ and $h_{M, t}$ are $3 \times 1$ vectors that consist of the elements in the second and the third columns of $H_{t}$, respectively ${ }^{8}$. Finally, $z_{t}$ denotes the standardized residuals that are assumed to be identically and independently distributed with mean 0 and variance 1 .

Parameters $\lambda_{M}$ and $\lambda_{X}$ are market price of risk and currency price of risk, respectively. $C$ is an upper triangular $3 \times 3$ matrix that contains the constants in conditional variance and covariance

\footnotetext{
Constant prices can be justified on the grounds that the suggested model is just a data generating process to obtain time-varying market and exchange rate exposure betas in terms of time-varying second moments.

7 The exchange rate is expressed as the local currency price of foreign currency and an increase implies a depreciation of the relevant currency relative to the other currencies.

8 Since we allow for non-orthogonality between market returns and exchange rate changes, a non-zero $h_{x m, t}$ term enters into mean equations for market returns and exchange rate changes.
} 
equations. Both $A_{k l}$ and $B_{k n}$ are $3 \times 3$ parameter matrixes. Although the use of a trivariate model offers the opportunity to capture the interdependence between the volatilities in terms of non-zero off-diagonal terms in parameter matrices, we make the restrictive assumption that parameter matrixes $A_{k l}$ and $B_{k n}$ are diagonal for two reasons. First, the full BEKK formulation is less parsimonious and computationally tedious ${ }^{9}$. Second, as the results of diagnostic tests reported in Section 5 show, the suggested diagonal version of the model sufficiently captures the non-linearities in stock returns and exchange rate changes. For parsimony, it is assumed that $K=1$. As a residual analysis based on the Ljung-Box statistic reveals, the optimal lag orders for GARCH and ARCH terms are as follows: $p=1, q=1$.

Time-varying betas can be obtained through Equations 7 and 8. In Equation 7, $H_{t}^{u u}, H_{t}^{v u}$ and are the conditional variance-covariance matrixes of the assets to be priced, the factors with which the assets are priced, and between the assets and factors, respectively.

Assuming that the standardized residuals of the suggested trivariate GARCH model are conditionally normally distributed, the conditional $\log$-likelihood of residual vector $\varepsilon_{t}$ at time $t$ can be defined as follows:

$$
\ell(\phi)_{t}=-\frac{1}{2} \ln (2 \pi)-\frac{1}{2} \ln \left|H_{t}\right|-\frac{1}{2} \varepsilon_{t}^{\prime} H_{t}^{-1} \varepsilon_{t}
$$

The log-likelihood function of the sample is obtained as $L(\phi)=\sum_{t=1}^{T} \ell(\phi)_{t}$, where $T$ is the number of observations. The parameter vector $\varphi$ of the trivariate BEKK-GARCH $(1,1,1)-\mathrm{M}$ model is estimated by maximizing $L$ with respect to $\varphi$. In order to accommodate the nonnormal features reflected in the basic statistics of country returns and exchange rate changes, all estimates of the parameters are obtained through the quasi-maximum likelihood (QML) estimation method proposed by Bollerslev and Wooldridge (1992). Under certain regularity conditions, the QML estimate is assumed to be consistent and asymptotically normal. Therefore, statistical inferences can be drawn due to robust standard errors. The required computer programmes are coded in GAUSS and use BHHH algorithm to compute QML estimates.

\section{Data}

The data relate to three emerging economies: Korea, Taiwan and Thailand. Weekly closing stock prices obtained on Wednesdays for the period from December 30, 1998 to 30

\footnotetext{
9 In our initial round of regressions, we found that the full BEKK model did not converge in some cases.
} 


\section{NSBM Journal of Management}

Vol. 1, No. 2, July-December, 2015

December 30, 2006 were used $^{10}$. The resultant sample period results in 418 observations. All stock indexes are from Morgan Stanley Capital International (MSCI) and extracted from Datastream. Country level portfolios are represented by MSCI country indexes measured in the relevant local currency. The world market portfolio is represented by the MSCI world market index MSWRLDL. It is a value-weighted world market index which is not converted into a common/reference currency and, therefore, free from exchange rate fluctuations (Giannopoulos, 1995; MSCI, 1998). All trade-weighted exchange rates are from J P Morgan and extracted from Datastream.

Continuously compounded weekly returns and exchange rate changes are calculated as follows:

$$
r_{j, t}=\ln \left(R_{j, t} / R_{j, t-1}\right) * 100 \quad j=i, m, x
$$

where $R_{j, t}$ and $R_{j, t-1}$ are the stock prices/exchange rates for the week $t$ and $(t-1)$ respectively. $i, m$ and $x$ denote the country in question, world market portfolio and the relevant exchange rate, respectively.

All return series show excess kurtosis which ranges from the lowest 0.4755 (Korea) to the highest 1.9398 (Thailand) ${ }^{11}$. The Jarque-Bera statistic is high in all cases except for Korea. Exchange rate changes show somewhat higher excess kurtosis ranging from 2.5770 (Taiwan) to 5.6381 (Thailand). In all three cases, excess kurtosis of the exchange rate changes is greater than that of the returns on the relevant country index. The high Jarque-Bera statistic together with excess kurtosis in some cases implies that the exchange rate changes are not normally distributed. The non-normal features of both country stock returns and exchange rate changes justify the use of the QML method of estimation.

As evidenced by the augmented Dicky-Fuller test, continuously compounded returns on all country indexes and the world market index and exchange rate changes are stationary. The Ljung-Box test for returns evaluated at 20 lags $(Q(20))$ reveals that there are no linear dependencies. Exchange rate changes for all three economies show the same pattern and are free from linear dependencies. However, the Ljung-Box test for squared returns evaluated

\footnotetext{
10 The financial crisis period is excluded from the sample in order to avoid the impact of unusual currency moments. Though we attempted to include Singapore and Australia in the sample, the exchange rate exposure coefficients of the country level stock returns of these economies are not significant for weekly return horizons.

11 To conserve space, results are not shown here.
} 
for 20 lags $\left(Q^{2}(20)\right)$ displays that all returns and changes in exchange rate series possess a great deal of non-linear dependencies. This provides some empirical support for the use of GARCH-type models to derive time-varying exchange rate exposure betas.

\section{Empirical Findings}

In this section, the results of a few tests that provide evidence for the likeliness of time-varying or unstable parameters in the selected sample have been reported. From this pre-estimation assessment, we move on to deriving time-varying exchange rate exposure coefficients and some diagnostic checks for adequacy of the proposed model to derive exposure coefficients. This is followed by a brief investigation of the stochastic structure of time-varying exposure coefficients.

\section{Some Pre-Estimation Results}

A few tests were used to show that countries selected the sample are more likely to possess timevariant (unstable) exchange rate exposure coefficients. All tests are based on OLS estimation of the conventional augmented market model that is widely used to estimate exchange rate exposure $^{12}$. The first such test is the cumulative sum of squared recursive residuals (CSSRR) test suggested by Brown et al. (1975). The CSSRR test is performed at the 5\% level of significance. During the sample period, the CSSRR crosses the critical value boundaries in all cases, thus suggesting the underlying parameter instabilities ${ }^{13}$. White's (1980) test for unconditional heteroskedasticity and ARCH-LM test for conditional heteroskedasticity are used to diagnose possible parameter instabilities. White's test statistic is significant in all cases except for Korea at 5 degrees of freedom at the significance level 1\%, suggesting the presence of unconditional heteroskedasticity. The ARCH-LM test statistic for 4 lags is significant for all the cases at the significance level $1 \%$. Results from all three tests suggest that the parameters in the specification represented by Equation 3 are highly likely to be time-variant.

\section{Time-Varying Exchange Rate Exposure Coefficients}

The maximum likelihood estimates for the suggested trivariate BEKK-GARCH $(1,1,1)-\mathrm{M}$ model are reported in Table 1. According to ICAPM reasoning, the market price of risk $\left(\lambda_{M}\right)$ must be positive and the same for all countries. However, there is no such restriction for the

\footnotetext{
12 This refers to the constant parameter version of the regression equation in (3).

13 To conserve space, results are not shown here.
} 


\section{NSBM Journal of Management}

Vol. 1, No. 2, July-December, 2015

currency price of risk $\left(\lambda_{X}\right)$. As the estimation results reported in the very first row of Table 1 indicate, $\lambda_{M}$ is positive and does not vastly vary across countries. More specifically, $\lambda_{M}$ is not statistically significant in any of these three cases. Unlike market price of risk, $\lambda_{X}$ varies remarkably across countries between the range 0.1623 (Korea) and 0.5657 (Taiwan). Since the relevant exchange rate varies across countries, this variation in the parameter can be understood. In all cases, currency price of risk is also not statistically significant ${ }^{14}$.

Table 1: Maximum Likelihood Estimates for the Proposed Model

\begin{tabular}{cccc}
\hline Coeff & Korea & Taiwan & Thailand \\
\hline$\lambda_{M}$ & 0.0094 & 0.0091 & 0.0218 \\
& $(0.31)$ & $(0.20)$ & $(0.63)$ \\
$\lambda_{X}$ & 0.1623 & 0.5657 & 0.2659 \\
& $(0.72)$ & $(0.82)$ & $(1.00)$ \\
$b_{i}$ & $0.9812^{*}$ & $0.9661^{*}$ & $0.9776^{*}$ \\
& $(211.38)$ & $(5.94)$ & $(66.03)$ \\
$a_{i}$ & $0.1706^{*}$ & 0.2406 & $0.1783^{*}$ \\
& $(6.45)$ & $(0.43)$ & $(2.70)$ \\
$b_{x}$ & $0.8840^{*}$ & $0.8266^{*}$ & $0.9265^{*}$ \\
& $(13.45)$ & $(4.02)$ & $(12.91)$ \\
\hline
\end{tabular}

Notes: The reader is referred to the set of Equations $4-8$ for the relevant model; t-values are in parenthesis; * indicates the significance at $\% 5$ level. Due to convergence problems, the sample period for Taiwan is taken as March 1, 1999-December 30, 2006.

Furthermore, all GARCH terms (denoted by $b_{j}$ for $j=i, m, x$ ) are highly significant, suggesting that the conditional variances are highly correlated to the past conditional variances. All ARCH terms (denoted by $a_{j}$ for $j=i, m, x$ ) are also significant except in one case suggesting the presence of volatility clustering in both stock and exchange rate markets of all three countries.

The diagnostic checks for the estimated model, results of which are not shown here for reasons of space, reveal that linear and non-linear dependencies have been adequately captured by the proposed trivariate BEKK GARCH(1,1,1)-M model. Ljung-Box statistics for standardized and squared standardized residuals evaluated for 20 lags $\left(Q(20)\right.$ and $Q^{2}(20)$ are not only well below the critical value of 31.481 at the $5 \%$ level, but are significantly lower than those of the return and exchange rate series. These results imply that the suggested model adequately filters linear and non-linear dependencies and is appropriate for deriving reliable estimates of time-varying exchange rate exposure betas.

14 These results are consistent with the previous findings in the literature. For instance, De Santis and Gerard (1998) and Cappiello et al. (2003) also find that both market and currency premiums are insignificant as long as the prices are not allowed to be time-variant. 
Time-Varying Exchange Rate Exposure: Evidence From Emerging Markets

\section{The Stochastic Structure of Exchange Rate Exposure Coefficients}

Table 2 compares the mean values of time-varying exchange rate exposure betas and their OLS point estimates. The mean value of each series is reasonably close to the relevant OLS point estimate.

Summary statistics of exchange rate exposure betas are reported in Panel A of Table 3. Standard deviation of exposure beta series ranges from 0.3885 (Korea) to 0.7447 (Taiwan). All exposure beta series are positively skewed and leptokurtic. A comparison between Panel $\mathrm{A}$ and $\mathrm{B}$ in Table 3 indicates that the standard deviation of exchange rate exposure beta is usually higher than that of market beta. In all three cases, kurtosis of each exposure beta distribution is also always higher than the kurtosis of its counterpart market beta distribution. This suggests that an exposure beta distribution tends to have more outliers than the outliers in its counterpart market beta distribution.

Table 2: OLS Point Estimates of Betas and the Mean Values of Time-Varying Coefficients

\begin{tabular}{lcccc}
\hline Country & Market beta & \multicolumn{3}{c}{ Exchange Rate Exposure beta } \\
& OLS $\beta_{\mathrm{m}}$ & Mean of $\beta_{\mathrm{m}, \mathrm{t}}$ & OLS $\beta_{\mathbf{x}}$ & Mean of $\beta_{\mathrm{x}, \mathrm{t}}$ \\
\hline Korea & 0.8807 & 1.0516 & 1.2112 & 0.9318 \\
Taiwan & 0.7084 & 0.8813 & 2.0817 & 1.7347 \\
Thailand & 0.6227 & 0.7616 & 1.6996 & 1.4858 \\
\hline
\end{tabular}

Table 3

Panel A: Preliminary Statistics of Time-Varying Exchange Rate Exposure Coefficients

\begin{tabular}{lccc}
\hline Coefficient & Korea & Taiwan & Thailand \\
\hline Mean & 0.9318 & 1.7347 & 1.4858 \\
Maximum & 2.2004 & 5.3367 & 4.9305 \\
Minimum & -0.0916 & 0.0310 & 0.0439 \\
S D & 0.3885 & 0.7447 & 0.7195 \\
Skewness & 0.3480 & 2.1149 & 1.7795 \\
Kurtosis & 3.1422 & 9.4108 & 9.0372 \\
J-B stat & 8.74 & 973.33 & 851.34 \\
\hline
\end{tabular}


NSBM Journal of Management

Vol. 1, No. 2, July-December, 2015

Panel B: Preliminary Statistics of Time-Varying Market Betas

\begin{tabular}{lccc}
\hline Coefficient & Korea & Taiwan & Thailand \\
\hline Mean & 1.0517 & 0.8823 & 0.7616 \\
Maximum & 1.6052 & 1.3209 & 1.6454 \\
Minimum & 0.4760 & 0.2796 & 0.2501 \\
S D & 0.2322 & 0.2019 & 0.3049 \\
Skewness & -0.2576 & -0.3678 & 0.5402 \\
Kurtosis & 2.4129 & 2.8611 & 2.7460 \\
J-B stat & 10.57 & 9.24 & 21.35 \\
\hline
\end{tabular}

Figure 1 provides a visual glimpse of all time-varying exposure coefficients. Since estimates of weekly time-varying betas may be 'still volatile and inevitably subject to estimation error' (De Santis \& Gerard 1998), the Hodrick-Prescott filtered trends of betas are also included in Figure 1. Each exposure beta seems to fluctuate within a wide range.

Figure 1: Time-varying Exchange Rate Exposure Coefficients

(a) Korea

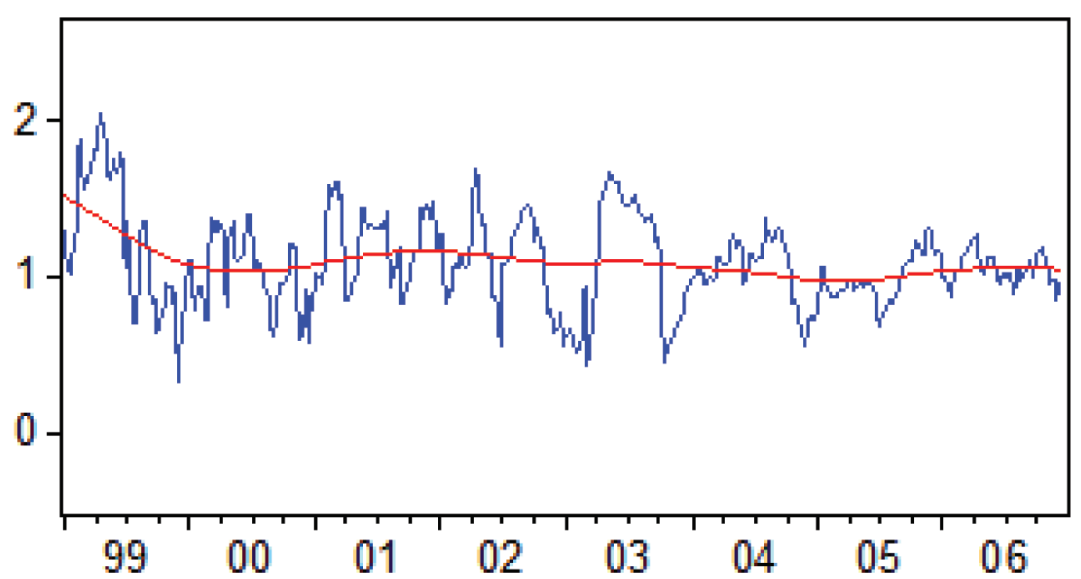


(b) Taiwan

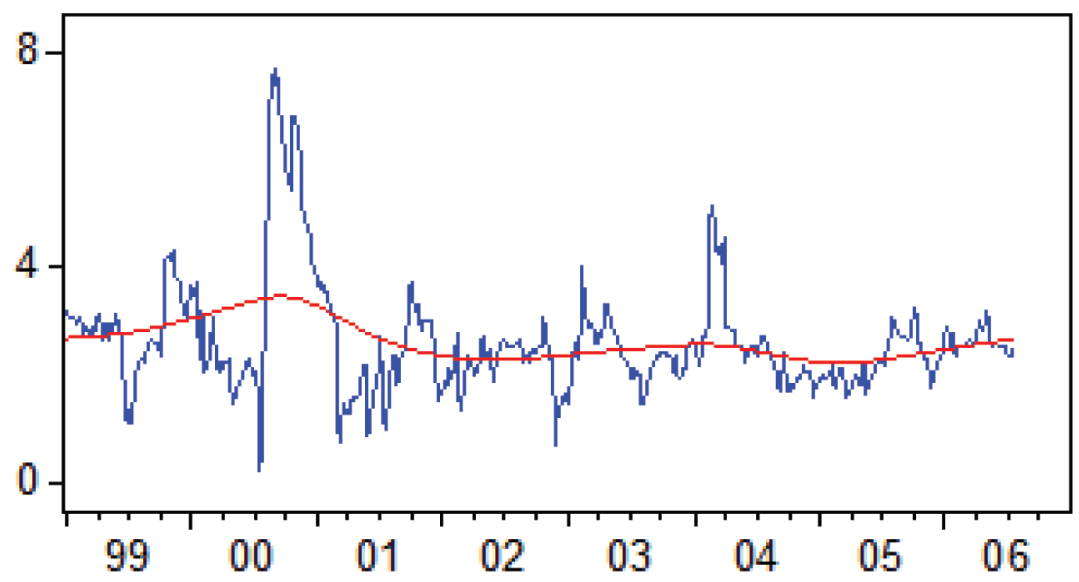

(c) Thailand

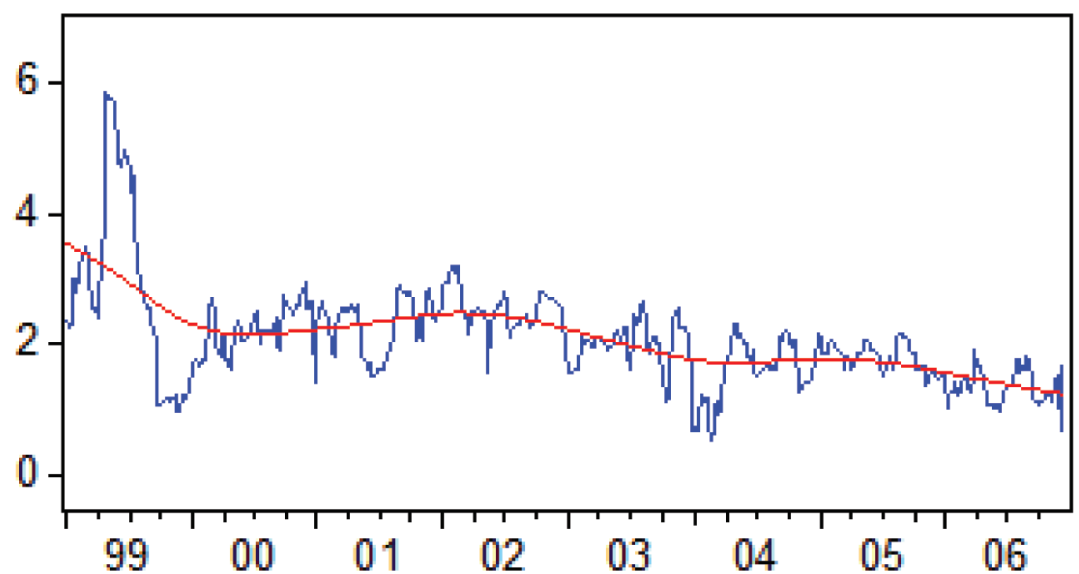

Next, whether the exchange rate exposure coefficients are mean-reverting and stationary was examined. Widely used semi-nonparametric Gewek and Porter-Hudak (1983) test was employed for this purpose ${ }^{15}$. In order to see the sensitivity of the estimates of the fractional difference parameter $d$ to the choice of $\alpha$, three values of $\alpha$ were used here: $0.50,0.55$ and

$15 \operatorname{In} I\left(\omega_{s}\right)=c+\phi \operatorname{In}\left(4 \sin ^{2}\left(\omega_{s} / 2\right)\right)+\zeta$ for $\mathrm{s}=1,2, \ldots \ldots \mathrm{n}(\mathrm{T})$ where $T$ is the number of observations in the series concerned; $I\left(\omega_{s}\right)$ is the periodogram of a series at harmonic frequency $\omega_{s}=(2 \pi s / T)$ with $s=(1,2, \ldots . . T-1 ; \zeta$ is random error; $n$ represents the number of low frequency ordinates and is usually determined as $n=T^{\alpha}$. OLS estimation of $\phi$ provides a consistent estimate of $-d$ in the ARFIMA process $\phi(L)(1-L){ }^{d} y_{t}=\Theta(L) v_{t}$ where $v_{t} \sim\left(0, \sigma^{2}\right)$. 
0.60 . First, a one-sided test was performed to check the validity of the null hypothesis of $d=0$ against the alternative of $d>0$. The null was rejected at the $5 \%$ level for all three cases suggesting that all exposure coefficient series are more likely to be represented by an ARFIMA process. Then a second one-sided test was performed for the null hypothesis of $d=1$ against the alternative of $d<1$. Test results for exchange rate exposure coefficient are reported in Table 4 . The null is rejected at the 5\% level for Korea and Taiwan under all three $\alpha$ values. However, null is accepted under all three $\alpha$ values for Thailand suggesting the presence of unit roots. Korea shows a difference parameter $d$ that is less than 0.5 when $\alpha=0.5$ and $\alpha=055$. Taiwan shows a difference parameter $d$ that is less than $\alpha=0.5$ only when .

Table 4: GPH Test Results for Time-Varying Exchange Rate Exposure Coefficients

\begin{tabular}{lccc}
\hline Country & \multicolumn{3}{c}{ Value of difference parameter $\boldsymbol{d}$} \\
& $\alpha=0.50$ & $\alpha=0.55$ & $\alpha=0.60$ \\
\hline Korea & $0.3331^{*}$ & $0.3314^{*}$ & $0.5932^{*}$ \\
\multirow{2}{*}{ Taiwan } & $(-2.74)$ & $(-3.74)$ & $(-2.51)$ \\
& $0.4638^{*}$ & $0.6836^{*}$ & $0.5896^{*}$ \\
Thailand & $(-4.07)$ & $(-2.28)$ & $(-3.68)$ \\
& 0.8189 & 0.8275 & 0.7914 \\
& $(-0.89)$ & $(-1.03)$ & $(-1.67)$ \\
\hline
\end{tabular}

Notes: $d$ represents $\phi$ in the regression equation; In $I\left(\omega_{s}\right)=c+\phi \operatorname{In}\left(4 \sin ^{2}\left(\omega_{s} / 2\right)\right)+\zeta ; t$-statistics are in parentheses; * indicates the significance at least at the $5 \%$ level

The findings from the GPH test can be summarized as follows. First, all time-varying exchange rate exposure coefficient series consistently reject hypothesis $I(0)$. It suggests that all exposure coefficients in the sample are characterized by a $I(d)$ process with $0<d<1$ or a unit root process. Second, in the case of Korea and Taiwan, hypothesis $I(1)$ is rejected. The fact that the difference parameter $d$ for exposure beta series in those two countries is greater than 0 and less than 1 implies that they are mean-reverting. However, the impact of a shock on exposure betas is likely to decay hyperbolically, which is much slower than a rapid geometric decay represented by a standard ARMA process. On the contrary, hypothesis $I(1)$ is accepted for Thailand meaning that the difference parameter $d$ for exposure beta is more likely to be greater than 1 . Third, though exposure betas of Korea and Taiwan are meanreverting, they are more likely to show covariance non-stationary dynamics. 


\section{Overall Implications}

Evidence for time-varying exchange rate exposure partly explains why past studies that use time-invariant exchange rate exposure beta estimation techniques show a lack of evidence for exchange rate exposure at firm, industry and country level. Incorporating the time-varying nature of exchange rate exposure into investment decision making are more likely to improve the accuracy of their decisions.

Exposure beta associated with the relevant trade-weighted exchange rate is positive in all three emerging markets. The intuition is that importers or investors whose consumption basket consists of a lot of imported goods from these countries cannot hedge against currency risk by investing in stocks in those markets. This is because returns on stocks in those countries are positively correlated with the depreciation of local currency (or appreciation of the importers' currency). However, the exporters to these economies can hedge against currency risk by investing in stocks in these emerging markets for the same reason.

As the GPH test results show, exposure betas of Korea and Thailand are likely to be meanreverting whereas those of Thailand are not. Mean-reverting exchange rate exposure betas have both theoretical and empirical implications. First, since returns are linear functions of betas (that represent exposure to market risk, currency risk or any other risk), it is argued that mean reverting betas are an essential element in ensuring the stationarity of returns. Second, the absence of mean reversion makes the notion of equilibrium have little relevance even in the long-run (Lai, 1997). Third, mean reverting exposure betas imply that these coefficients can be used for forecasting purposes. This may be extremely important news for hedging against currency risks.

Derived exchange rate exposure beta series (or distributions) can be used as a useful source of data for further analyses which are helpful for those who are engaged in cross-country investments in their decision making. First, those series can be used to compare the exchange rate risk between countries using the stochastic dominance criterion . Second, time varying market and exchange rate exposure betas can be used to examine the relationships among market, currency and total risk premiums in each country.

\section{Concluding Remarks}

A trivariate BEKK-GARCH $(1,1,1)-\mathrm{M}$ model based on a conditional ICAPM framework has been used to obtain time-varying exchange rate exposure betas. This approach does not require a prior understanding of the determinants of the time-variation of exposure beta to 


\section{NSBM Journal of Management}

Vol. 1, No. 2, July-December, 2015

obtain the estimates of the same. Also, the suggested approach is more appropriate than the GARCH-based methods that use inappropriate mean structures in deriving time-varying betas. As the mean structure in such models does not represent a relevant ICAPM, the resultant information loss may lead to inaccurate estimates.

In deriving time-varying exchange rate exposure betas, the need to take the non-orthogonality between exchange rate changes and market returns into account has been emphasized. A portion of exchange rate exposure is always captured by market beta and is also priced under the label of market risk. What counts for the decisions of firms and investors is the portion of exchange rate exposure that is not captured by market beta and hence not priced under market risk. As such, the estimated time-varying exchange rate exposure betas are more reliable than those in the studies that do not take this non-orthogonality into account.

The examination of the stochastic structure of the time-varying exchange rate exposure betas offers some useful insights. As evidenced by their basic statistics, exposure betas are usually more volatile than market betas. And, as compared to the market beta series for each economy, exposure beta series tend to have more outliers. Results from the GPH test reveal that exposure betas of Korea and Taiwan are long-memory processes characterized by fractional integration. Exposure beta in both cases turns out to be mean-reverting though their mean reverting dynamics could be highly persistent and display a slow hyperbolical decay. As for the covariance stationarity, however, we did not obtain unambiguous results and the matter is left for future research. Exposure beta of Thailand is characterized by a unit root process and non-stationarity.

A possible limitation of the study is that these conclusions are based on the sample period from December 30, 1998 to December 39, 2006. However, two remarks in relation to this are worth mentioning. First, as mentioned in Section 5, selection of this sample period was partly due to the need to avoid the period of financial crisis, during which the behaviour of the variables in question were far from normal. Second, though the reliance on an old data set may look like a data mining attempt in suggesting the presence of time-varying exchange rate exposure in those markets, it hardly matters in demonstrating a more appropriate approach to compute time-varying currency betas and analyze their stochastic structure, which is the main contribution of this paper to the literature. 


\section{References}

Adler, M \& Dumas, B 1983, 'International portfolio choice and corporation finance: a synthesis', Journal of Finance, vol. 88, no. 3, pp. 925-984.

Allayannis, G 1997, 'The time-variation of the exchange rate exposure: an industry analysis', Working Paper, University of Virginia, pp. 97-29,

Allayannis, G \& Ihrig, J 2001, 'Exposure and mark-ups', Review of Financial Studies, vol. 14, no. 3, pp. 905-935.

Bodnar, GM \& Wong, MFH 2003, 'Estimating exchange rate exposures: issues in model structure', Financial Management, Spring, pp. 35-67.

Bodnar, GM \& Gentry, WM 1993, 'Exchange rate exposure and industry characteristics: evidence from Canada, Japan and the USA', Journal of International Money and Finance, vol. 12, pp. 29-45.

Bollerslev, T \& Wooldridge,JM 1992, 'Quasi-maximum likelihood estimation and inference in dynamic models with time-varying covariances', Econometric Reviews, vol. 11, pp. 143-179.

Brown, R, Durbin, J \& Evans, JM 1975, 'Techniques for testing the constancy of regression relationships over time', Journal of the Royal Statistical Society, vol. 37, pp. 145-164.

Cappiello, L, Castren, O \& Jaasakela, J 2003, 'Measuring the Euro exchange risk premium: the conditional international CAPM Approach,' Working Paper, European Central Bank.

Chiao, C \& Hung, K 2000, 'Exchange rate exposure of Taiwanese exporting firms', Pacific Basin Finance Journal, vol. 6, pp. 153 - 174.

Chow, EH \& Chen, HL 1998, 'The determinants of foreign exchange rate exposure: evidence from Japanese firms', Pacific Basin Finance Journal, vol. 6, pp. 153-174.

De Santis, G \& Gerard, B 1998, 'How big is the premium for currency risk?', Journal of Financial Economics, vol. 49, pp. 375-412.

Dominguez, KME \& Tesar, LL 2006, 'Exchange rate exposure', Journal of International Economics, vol. 68 , pp. $188-218$.

Dominguez, KME \& Tesar, LL 2000, 'Trade and exposure', American Economic Review, vol. 91, no. 2, pp. 367-370.

Entorf, H \& Jamin, G 2003, 'German exchange rate exposure at DAX and aggregate level, international trade, and the role of exchange rate adjustment costs', Darmstadt Discussion Papers in Economics \# 126.

Gewek, J \& Porter-Hudak, S 1983, 'The estimation and application of long memory time series models', Journal of Financial and Quantitative Analysis, vol. 13, pp. 101-116.

Giannopoulos, K 1995, 'Estimating the time varying components of international stock markets' risk', European Journal of Finance, vol. 1, pp. 129-164.

Giurda, F \& Tsavalis, E 2004, 'Is the currency risk priced in equity markets?', Working Paper \# 511, Queen Mary University of London.

Harvey, CR 1991, 'The world price of covariance risk', Journal of Finance, vol. 46, pp. 111-157. 
NSBM Journal of Management

Vol. 1, No. 2, July-December, 2015

Hunter, DM 2005, 'Time-varying exchange rate exposure of small and large firms', Working Paper, University of South Florida.

Jayasinghe, P, Tsui AK \& Zhang Z 2014, 'New estimates of time-varying currency betas: a trivariate BEKK approach', Economic Modelling, vol. 42, pp. 126-139.

Lai, KS 1997, 'Long-term persistence in the real interest rate: some evidence on a fractional unit root', International Journal of Financial Economics, vol. 2, pp. 225-235.

Lim, GC 2005, 'Currency risk in excess equity returns: a multi time-varying beta approach', International Financial Markets, Institutions and Money, vol. 15, pp. 189-207.

Long, L, Tsui, AK \& Zhang, Z 2014, 'Estimating time-varying currency betas with contagion: New evidence from developed and emerging financial markets', Japan and the World Economy, vol. 30, pp. $10-24$

MSCI 1998, Methodology and index policy, Morgan Stanley Capital International.

White, H 1980, 'A Heteroskedasticity-consistent covariance estimator and a direct test for Heteroskedasticity', Economica, vol. 48, pp. 817-838.

Williamson, R 2001, 'Exchange rate exposure and competition: evidence from the automotive industry', Journal of Financial Economics, vol. 59, no. 3, pp. 441-475. 